\title{
COMPARATIVE EFFECTS OF ETHANOL EXTRACT OF TALINUM TRIANGULARE AND ASCORBIC ACID ON DI-2-ETHYLHEXYL PHTHALATE INDUCED UNDESCENDED TESTIS IN WISTAR RATS
}

\author{
Olakayode Olaolu Ogundoyin ${ }^{1,2}$, Anne Fiyinfoluwa Sanwo \\ 1. Department of Surgery, College of Medicine, University of Ibadan, Ibadan, Nigeri \\ 2. Department of Anatomy, College of Medicine, University of Ibadan, Ibadan, Nigeria
}

Correspondence to Dr Olakayode O. Ogundoyin Department of Surgery, College of Medicine, University of Ibadan, Ibadan, Nigeria. Email: - kayogundoyin@gmail.com. Phone: - +234-803-4033-724

\begin{abstract}
This study compared the effects of Talinum triangulare extract and Ascorbic acid on the oxidative stress caused by Di-2-ethylhexyl-phthalate (DEHP) induced undescended testis (UDT) in Wistar rats. Twenty-four pregnant rats were randomly divided into six groups of four animals each. Group 1 (Control) received $2.5 \mathrm{ml} / \mathrm{kg}$ corn oil for 21 days, Group 2 received $750 \mathrm{mg} / \mathrm{kg}$ DEHP on gestational days (GD) 14-18, Group 3 received 200mg/kg ascorbic acid for 21 days and 750mg/kg DEHP from GD 14-18 and Group 4 received 200mg/kg Talinum triangulare extract for 21 days and 750mg/kg of DEHP from GD 14-18. The dams were delivered, the resulting pups weighed and sacrificed on postnatal day (PND) 28. Gross examination of the pups, biochemical and histological changes were recorded. Data were analyzed using One-way ANOVA. Group 2 pups had UDT and low birth weight compared to other groups. The mean testicular weight and anogenital distance (AGD) were low in Group 2 pups compared to pups in Groups 3 and 4. The mean values of all the antioxidant enzymes and serum testosterone were low in Group 2 pups compared to other groups. Histological examination of the testes of Group 2 pups revealed moderate vascular congestion within the tunica albuginea and severe atrophy of seminiferous tubules with degenerated Sertoli cells compared to normal findings in other Groups. Although the ameliorative effects of Talinum triangulare is not as potent as that of Ascorbic acid, preconceptional and continuous intake of this vegetable by pregnant women would help to prevent UDT and other associated problems.

Keywords: Oxidative stress, Talinum triangulare, testosterone, Undescended testis, Ascorbic acid.
\end{abstract}

\section{INTRODUCTION}

Undescended testis (UDT) is one of the commonest congenital anomalies encountered in the pediatric population and it is estimated to affect $1-4 \%$ of full term and up to $30 \%$ of preterm male neonates (Chung and Brock, 2011). It is characterized by testes that do not follow the normal developmental pattern of moving into the scrotum from its original abdominal position before birth. Complications like infertility and testicular cancer can occur later in life, therefore early management is inevitable (Chung and Brock, 2011). Although the exact aetiology of this pathology is unknown, the causes of UDT are multifactorial
(Hutson et al., 2013). Various theories have therefore been put forward about the mechanism involved in normal and abnormal testicular descent, with persuasive evidence that endocrine, anatomical, genetic and environmental factors are involved during this process (Virtanen et al., 2007). Most environmental chemicals are hormonally active compounds that target the endocrine system and cause reproductive anomalies (Cravedi et al., 2007), some of which are known to disturb the testicular environment (Mathur and D'Cruz, 2011). These chemicals are termed hormonally active agents, environmental oestrogens, 
hormone mimics, and endocrine disrupters/disruptors. Endocrine disruptors are probably the best-known environmental toxicants because they disrupt the endocrine and reproductive systems, which regulate growth, development, sexual maturity and brain function in organisms. Human beings and wildlife are exposed to a complex milieu of these chemicals from sources including food, water, personal care products, occupation and the environment.

Environmental exposure to Di 2-ethylhexyl phthalate (DEHP), a known endocrine disruptor is believed to interfere with the development of male external genitalia and descent of the testis. Di 2-ethylhexyl phthalate is a manufactured chemical commonly added to plastics for flexibility and does not evaporate easily. As a result of its wide use in cosmetics, plastics, food packaging and medical device, human beings are constantly exposed through oral, dermal and inhalation routes (Mathur and D'Cruz, 2011). Di 2-ethylhexyl phthalate possess endocrine activity and they act as antiandrogens without interacting directly with androgen receptor (Parks et al., 2000). It has been shown that DEHP also inhibit testosterone production by fetal Leydig cells in rodents (Park s et al., 2000, Barlow et al., 2003, Borch et al., 2004, Wilson et al., 2004, Lehman et al., 2004). Oxidative stress is a common pathological process involved in the mechanism of DEHPinduced testicular injury, which makes it possible to have oxidative stress monitoring as an informative way to study interactions between numerous toxicants and the reproductive consequences (Silins and Hogberg, 2011, Aitken et al., 2014). Although, the mechanisms by which DEHP exerts its toxic effects in male reproductive system have not been fully elucidated (Erkekoglu et al., 2010), it causes oxidative stress by inducing release of reactive oxygen species (ROS) and/or impairing antioxidant defenses (Kashara et al., 2002,

\section{MATERIALS AND METHODS}

Di 2-ethylhexyl phthalate (DEHP) was procured from Sigma Aldrich, Germany. Fresh leaves of
Erkekoglu et al., 2010, Zhao et al., 2012, Tetz et al., 2013), increases lipid peroxidation in cultured rat hepatocytes, induces testicular atrophy, decreases cellular levels of antioxidants (Kashara et al., 2002) and during pregnancy may also lead to undescended testes (Damgard et al., 2006, Thorup et al., 2006). Furthermore, DEHP also causes testicular malformations induced by maternal and neonatal exposures to this compound (Gray Jr et al., 2000).

Ascorbic acid or Vitamin C is a water-soluble, chain-breaking antioxidant (Uchendu et al., 2012). It is one of the most widely available and affordable non-enzymatic antioxidant molecules that have been used to mitigate oxidative damage (Naidu, 2003). It readily scavenges physiological ROS as well as reactive nitrogen species (RNS) (Uchendu et al., 2012). This readily available, cheap and relatively nontoxic antioxidant possesses great potential benefit in the amelioration of toxic effects exerted by some of these environmental toxicants (Uchendu et al., 2012). On the other hand, vegetables and fruits also contain high concentration of numerous redox-active antioxidants such as polyphenols, carotenoids, ascorbic acids, tocopherol and flavonoids which fight against hazardous oxidative damage of plant cells (Olajire and Azeez, 2011). Talinum triangulare, a green leafy vegetable has been reported to have anti-oxidant property (Folarin et al., 2001) and also used in the treatment of diseases. The presence of minerals such as calcium, magnesium and potassium, omega-3fatty acid vitamin $C, E$ and betacarotene have been identified to be responsible for the antioxidant activity of the leaf (Ezekwe et al., 2013).

This study aimed at investigating and comparing the preventive effects of Talinum triangulare extract and ascorbic acid as potential antioxidants in DEHP induced undescended testis in rats.

water leaf (Talinum triangulare) were identified and authenticated at Botany Department, 
Faculty of Science, University of Ibadan with a voucher specimen reference number UIH22515. Extraction of the leaf was carried out at the Department of Pharmaceutical Chemistry, Faculty of Pharmacy, University of Ibadan and Ascorbic acid tablets 500mg (Vitamin C - Mason Nature, USA) was procured from the pharmacy. Each tablet was crushed and dissolved in $10 \mathrm{ml}$ of distilled water and administered orally. Following ethical approval by the University of Ibadan Animal Care and Use Research Ethics Committee (UI-ACUREC), thirty - adult female Wistar rats weighing $100-120 \mathrm{~g}$ were acclimatized for 2 weeks in well ventilated cages and allowed free access to feed and water ad libitum. A randomly selected male rat was paired with 3 randomly selected female rats on heat for not more than a week. On the morning of each mating day, the female rats were examined daily for vaginal plug and microscopically for the presence of sperm cells. The animal was considered pregnant if spermatozoa were observed from the smear microscopically and the confirmed pregnant rat was moved into a separate cage and marked as GD 0.

Group 1: Control dams received $2.5 \mathrm{ml} / \mathrm{kg}$ corn oil daily for 21 days.

Group 2: Dams that received DEHP only with a dose of $750 \mathrm{mg} / \mathrm{kg}$ daily on GD $14-18$ by oral gavage.
Group 3: Dams received $750 \mathrm{mg} / \mathrm{kg}$ DEHP between GD $14-18$ orally and $200 \mathrm{mg} / \mathrm{kg} /$ day Ascorbic acid for 21 days.

Group 4: Dams that received $200 \mathrm{mg} / \mathrm{kg}$ of Talinum triangulare extract daily for 21 days and $750 \mathrm{mg} / \mathrm{kg}$ of DEHP on GD 14-18.

All pups were sacrificed 3-4 weeks after birth (PND 21-28). Body and testicular weights of the pups were recorded from each group. On postnatal day (PND) 28, all pups were weighed, examined and Anogenital distances (AGD) were measured with a Venier caliper (NHBS Ltd, U.K). Male rats were then assessed for reproductive tract alteration including undescended testes, cleft phallus, hypospadias, epididymal agenesis, testicular atrophy, fluid filled testes, ventral prostate or seminal vesicle agenesis and malformations of the gubernacular cords (elongated or absent). Photographs were taken; foetal mortality and serum testosterone level were recorded. Testicular tissues were processed for histological studies using haematoxylin and eosine (H\&E) staining technique. All values were expressed as mean \pm SD using One-way ANOVA with the aid of Graph Pad Prism Software Version 7.02. The level of statistical significance was taken to be $p<0.05$.

\section{RESULTS}

There were no abnormalities or physical alterations seen across the groups except for retarded growth observed in Groups 2 (DEHP only), 3 (Ascorbic acid with DEHP) and 4 (Talinum triangulare with DEHP). Growth retardation was assessed by weekly observation of their weights and their physical appearance from PND1-28. Hypospadias was observed in 4 pups in DEHP treated group. On physical examination of the scrotum at PND 28, pups in Group 1 had completely descended testes whereas the testes of the pups in Groups 3 and 4 were not completely descended (Figure 1 A - D). The pups in Group 2 displayed complete undescended testes. 

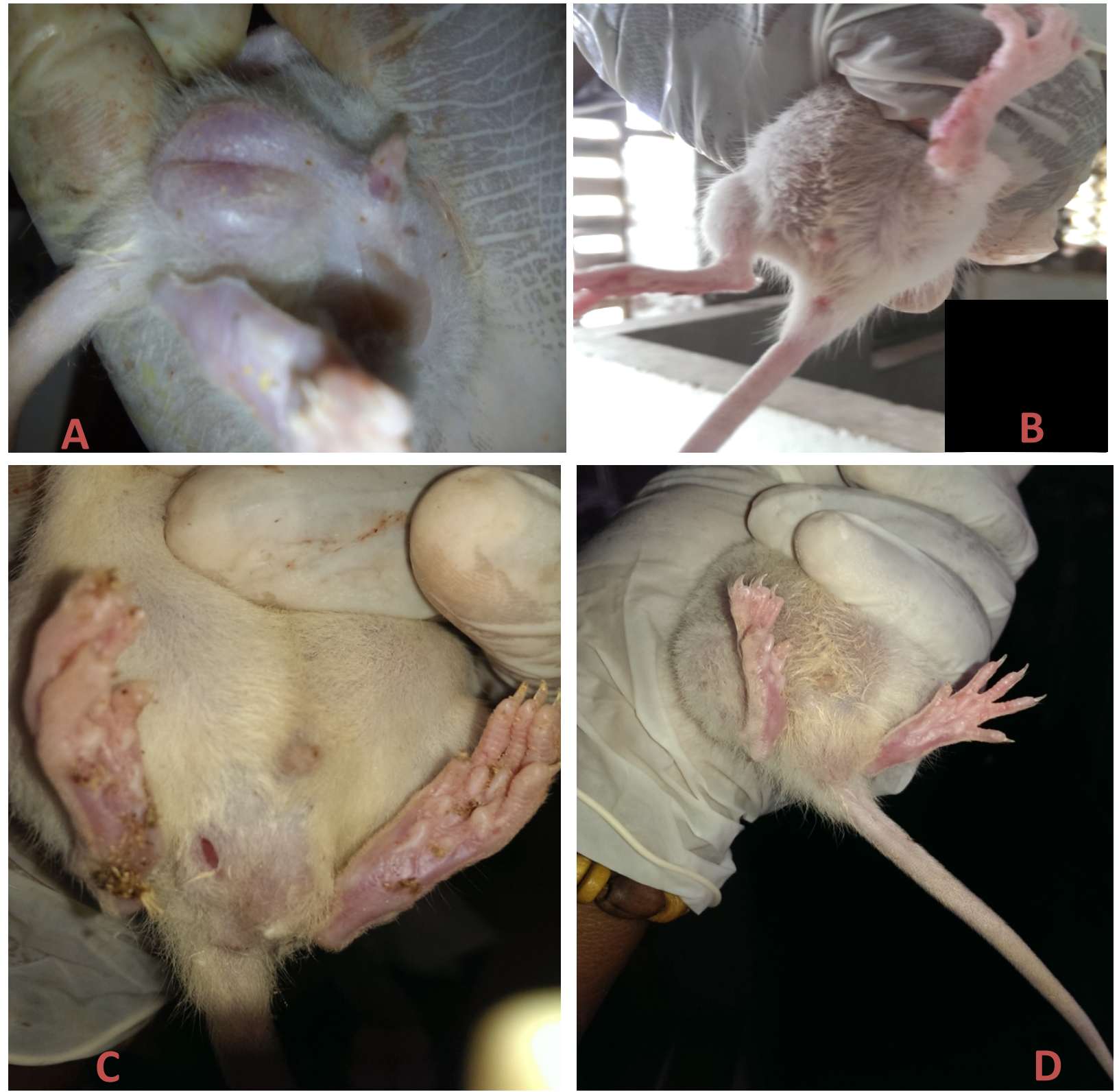

Fig 1A - D: The positions of the testes on postnatal day 28. A - Group 1(Control) pups with complete descent of the testes. B - Group 2 (DEHP Only) pups with complete undescended testes and short anogenital distance. C (Group 3 - Ascorbic acid + DEHP) and D (Group 4 - Talinum triangulare + DEHP) pups with incomplete descent of the testes.

Groups 3 and 4 pups had considerably low birth weights (3.86 \pm 0.25 vs $3.94 \pm 0.58$ respectively) in comparison to pups in Groups 1 and 2 (6.01 $\pm 0.03 \& 4.89 \pm 0.24$ respectively). There was a considerable increase in mean weight of the pups in Groups 3 and 4 at PND 28 (50.66 \pm 5.34 and $44.36 \pm 8.16$ respectively) in comparison to Group 2 pups with the lowest mean weight of $36.79 \pm 2.82$. The mean weights of the pup at birth and before sacrifice were statistically significant $(p<0.05)$. The mean anogenital distance (AGD) was significantly reduced in Group 2 pups (1.44 \pm $0.21)$ whereas pups in Groups 3 (2.02 \pm 0.08$)$ and 4 (2.06 \pm 0.27$)$ showed rapid increase in their mean AGD in comparison to pups in Group 2 (Table 1). 
Table 1: Mean anogenital distance, weight at birth and at Postnatal day (PND) 28

\section{Parameters}

Mean birth weight ( $g$ )

Mean birth weight at PND $28(\mathrm{~g})$

Mean anogenital distance $(\mathrm{cm})$

\section{Group 1}

$6.01 \pm 0.03$

$71.89 \pm 5.86$

$2.58 \pm 0.19$

\section{Group 3}

$4.89 \pm 0.24$

$36.79 \pm 2.82$

$1.44 \pm 0.21$
$3.86 \pm 0.25$

$50.66 \pm 5.34$

$2.02 \pm 0.08$

\section{Group 4}

$3.94 \pm 0.58$

$44.36 \pm 8.16$

$2.06 \pm 0.27$
A statistically significant reduction was recorded in serum testosterone levels of pups in Group 2 compared to Group 1. There was an improvement in the values obtained in Groups 3 and 4 in comparison to Group 2. There was no statistically significant difference between the experimental groups and control group. There was a significant reduction in the serum levels of all the antioxidant enzymes in the pups of Group 2 compared to the Control group but no significant difference in the serum levels of the enzymes of Group 2 pups in comparison to the pups in Groups 3 and 4. Also, ascorbic acid appears to have a more stabilizing effect on the antioxidant enzymes and thus reduce the incidence of oxidative stress caused by DEHP in comparison with Talinum triangulare but there was no significant difference in the ameliorative effects of ascorbic acid and Talinum triangulare on the induction of oxidative stress in the testes of pups treated with DEHP in both Groups 3 and 4 (Table 2).

Histological examinations of the testes of the pups across the groups revealed normal seminiferous tubules, spermatogonia and sertoli cells in Groups 1 (Control), 3 (Ascorbic acid + DEHP) and 4 (Talinum triangulare + DEHP) pups whereas there were severe atrophy of the seminiferous tubules with no germ cells and degenerated sertoli cells in the testes of the pups in Group 2 (Figure 2 A - D).

Table 2: Mean Serum levels of testosterone and antioxidant enzymes

Parameters

Testosterone
Malondialdehyde
Superoxide dismutase

Catalase levels

Glutathione peroxidase

\section{Group 1}

(Control)

$1.24 \pm 0.11$

$7.88 \pm 1.11$

$4.38 \pm 0.79$

$4.57 \pm 0.37$

$153.17 \pm 78.75$
Group 2

(DEHP Only)

$0.05 \pm 0.01$

$2.96 \pm 1.16$

$2.91 \pm 1.10$

$1.55 \pm 0.50$

$86.36 \pm 46.51$

\section{Group 3}

(Vit. C + DEHP)

$0.28 \pm 0.16$

$3.80 \pm 0.67$

$3.18 \pm 0.49$

$1.75 \pm 0.27$

$95.66 \pm 20.55$

\section{Group 4}

(TT + DEHP)

$0.13 \pm 0.07$

$4.45 \pm 1.82$

$3.57 \pm 0.74$

$1.60 \pm 0.61$

$80.25 \pm 12.57$ 

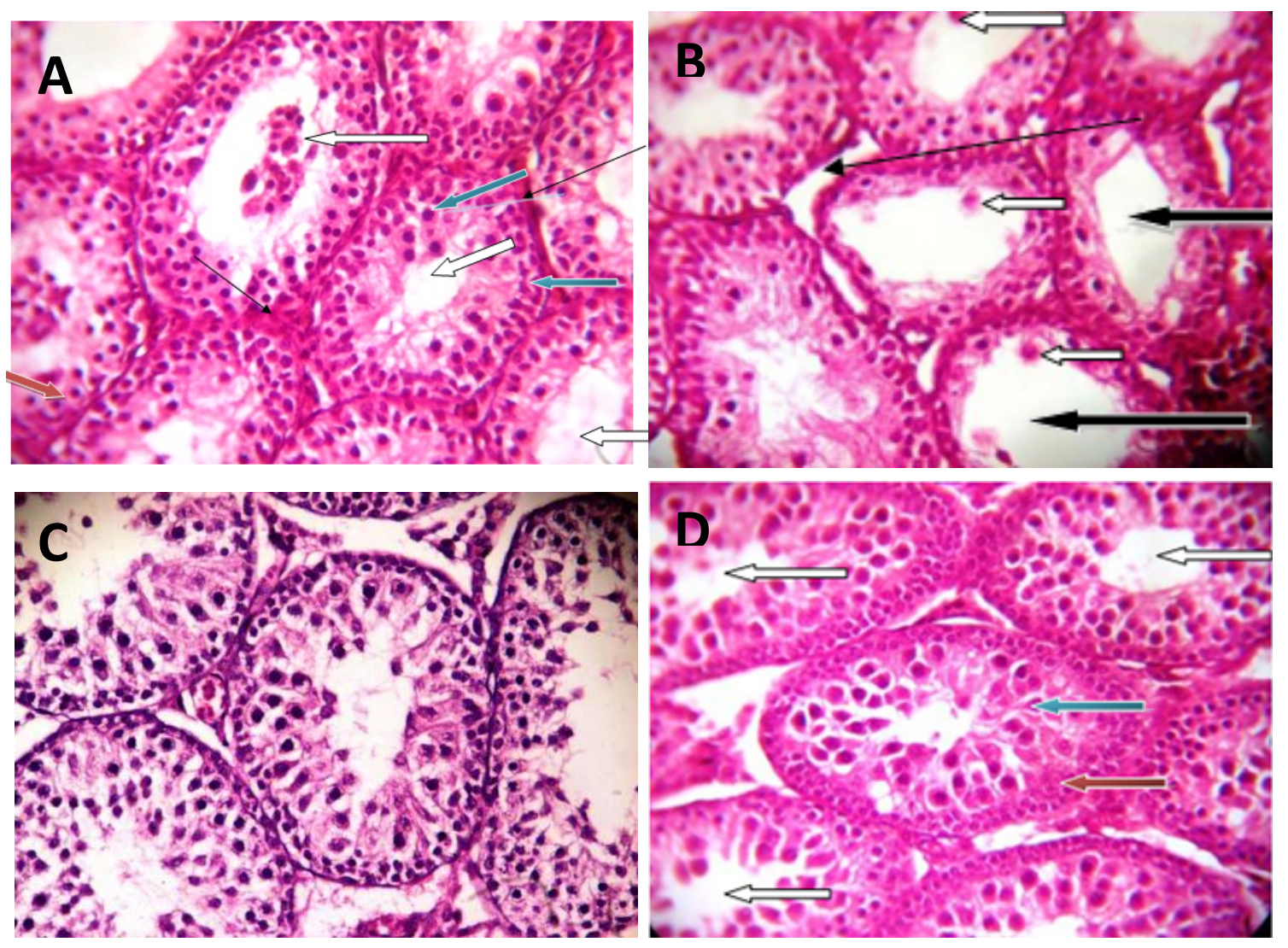

Figure 2 A - D (H\&E x400): Photomicrographs of testicular sections of rat pups. A - Group 1(Control) showing normal seminiferous tubules with normal spermatogonia cells (blue arrow) and normal sertoli cells (red arrow), although no maturation stages seen, the lumen appear widened with little spermatozoa (white arrow). The interstitial spaces and Leydig cells appear normal (slender black arrow). B - Group 2 (DEHP only) showing severely atrophied seminiferous tubules (black arrow), the tubules show lack of germ cells and degenerated sertoli cells (white arrow). The interstitial spaces appear normal few Leydig cells are seen (Slender arrow). C - Group 3 (Ascorbic acid + DEHP) showing normal seminiferous tubules with normal spermatogonia cell (blue arrow) and normal Sertoli cells (red arrow), there is no maturation stages seen, the lumen appear widened without spermatozoa (white arrow). The interstitial spaces and Leydig cells appear normal (slender arrow). D - Group 4 (Talinum triangulare + DEHP) showing normal seminiferous tubules with normal spermatogonia cell (blue arrow) and normal Sertoli cells (red arrow), gradual maturation is seen but no complete maturation stages seen, the lumen appear widened without matured spermatozoa (white arrow).

\section{DISCUSSION}

Di-2-ethylhexyl phthalate (DEHP) are a large group of chemicals used in plasticizers and industrial solvents for flexibility and solubility. These chemicals are especially common in the production of toys, medical equipment, rubber and drug coverings. It induces a multi-organ damage through a number of mechanisms such as reduction in testosterone levels (antiandrogenic effect), induction of oxidative stress via generation of ROS, DNA damage, lipid peroxidation, disrupting cell function, altering gene expression and activity of most important antioxidant enzymes. The current study demonstrates the overall effects of DEHP on the development of the testis of pups of pregnant wistar rats. It was therefore, established that $750 \mathrm{mg} / \mathrm{kg}$ of DEHP altered sexual differentiation in the male pups. Abortions of the foetus and death were also recorded at early stages of gestation; this could 
be due to the toxicity of the chemicals and/or pseudo-pregnancy. These are in consonance with other studies (Gray Jr et al., 2000, Hutson et al., 2013) where congenital undescended testis was induced by the plasticizer DEHP.

The pups had low body weight and at some point had retarded growth because they were not growing at the pace of their counterparts in the control group. This could be due to the presence of the toxic substance in the breast milk which was the major source of feeding for the pups for the period of the study. Anogenital distance (AGD) of DEHP-exposed males was significantly reduced at PND 28. This indicates feminization of the male reproductive characters. Anogenital distance is a sexual dimorphism that results from the sexual difference in fetal androgen levels. This result therefore indicates that DEHP treatment inhibited the effects of dihydrotestosterone on the differentiation of the sexually dimorphic endpoint (Parks et al., 2000). Testosterone is the critical hormone that maintains spermatogenesis in the testis and is also needed for male sexual differentiation. Administration of DEHP showed marked decrease in the serum testosterone levels. It is important to note that this alteration in the serum testosterone level confirms that DEHP produces antiandrogenic effects during fetal life. Though it was hypothesized by Gray Jr. et al., (2000) that it has anti-androgenic effects, it may not likely act by antagonizing the androgen receptors, but affects the gene expression (Parks et al., 2000). Considerable preventive effects were observed in both Ascorbic acid and Talinum triangulare.

This study has been able to show the damaging effects of DEHP on the testes which were mostly undescended in Group 2 pups. These effects were comparatively ameliorated by ascorbic acid and ethanolic extract of Talinum triangulare in Groups 3 and 4 pups with preservation of the cellular architecture of the testes that were mostly descended (Figure $2 \mathrm{C}$ and $\mathrm{D}$ ). The blockade of the antiandrogenic effects of DEHP by ascorbic acid and extract of Talinum triangulare with consequent normalization of serum testosterone levels which aids descent of the testis, differentiation of spermatogonia and the development of the seminiferous tubules may be responsible for the findings in these groups. Therefore, they may be useful as supplements during pregnancy to prevent occurrence of congenital undescended testis. Though they might have not shown substantial effect in increasing the serum testosterone levels, they can still help (especially Talinum triangulare) to maintain a considerable normal level compared to the damaging effects of DEHP. Although it has been established that ascorbic acid is a potent antioxidant (Dare et al., 2014) and Talinum triangulare also has some antioxidant properties (Aja et al., 2010), this study has not shown a significant individual antioxidant effects attributed to them as seen in the levels of the antioxidant enzymes in the DEHP treated Groups 3 and 4. However when ascorbic acid and Talinum triangulare are consumed together, the potential antioxidant effects may be synergistic and as such may ameliorate the oxidative effects of DEHP. In addition, these findings may be dose dependent as an increasing dosage of ascorbic acid and ethanolic extract of Talinum triangulare may be needed to counteract the oxidative effects of DEHP at the dosage used. Thus, in humans, pregnant women should maintain a healthy vegetable and fruit diet like Talinum triangulare as nutritional supplements and adequate preconceptional intake of this vegetable and ascorbic acid should be encouraged in other to reduce the incidence of undescended testis and oxidative stress produced within the testis.

In conclusion, although the ameliorative effects of Talinum triangulare is not as potent as that of Ascorbic acid, preconceptional and continuous intake of this vegetable by pregnant women would help to prevent UDT and other associated problems. 
Anatomy Journal of Africa. 2019. Vol 8 (2): 1531 - 1539.

\section{REFERENCES}

1. Aitken RJ, Smith TB, Jobling MS, Baker MA, De Iuliis GN. 2014. Oxidative stress and male reproductive health. Asian J Androl 16: 31-38.

2. Aja PM, Okaka ANC, Onu PN, Ibiam U, Urako A. J. 2010. Phytochemical Composition of Talinum triangulare (Water Leaf) Leaves. Pakistan J Nutrition 9(6): 527-530.

3. Barlow NJ, Phillips SL, Wallace DG, Sar M, Gaido KW, Foster PM. 2003. Quantitative changes in gene expression in fetal rat testes following exposure to di (n-butyl) phthalate. Toxicolog Sci. 73: 431-441.

4. Borch J, Ladefoged O, Hass U, Vinggaard AM. 2004. Steroidogenesis in fetal male rats is reduced by DEHP and DINP, but endocrine effects of DEHP are not modulated by DEHA in fetal, prepubertal and adult male rats. Reproduct Toxicol 18: 53-61.

5. Chung E, Brock GB. 2011. Cryptorchidism and its impact on male fertility: a state of art review of current literature. Canadian Urol Ass J 5: 210-214

6. Cravedi JP, Zalko D, Savouret JF, Menuet A, Jegou B. 2007. The concept of endocrine male disruption and human health. Med Sci (Paris) 23: 198-204.

7. Damgaard IN, Skakkebaek NE, Toppari J, Virtanen HE, Shen H, Schramm KW, Petersen JH, Jensen TK, Main KM. 2006. Nordic Cryptorchidism Study Group: Persistent pesticides in human breast milk and cryptorchidism. Environm Health Perspect 114:1133-1138.

8. Dare BJ, Oyeniyi F, Olaniyan OT. 2014. Role of Antioxidant in Testicular Integrity. Ann Res Rev Biol 4: 998-1023.

9. Erkekoglu P, Rachidi W, Yuzugullu OG. 2010. "Evaluation of cytotoxicity and oxidative DNA damaging effects of di(2-ethylhexyl)-phthalate (DEHP) and mono(2-ethylhexyl)-phthalate (MEHP) on MA-10 Leydig cells and protection by selenium," Toxicol Applied Pharmacol 248.1: 52-62.

10. Ezekwe CI, Okoro IJ, Ugwu OPC, Ezea SC. 2013. The effect of methanol extract of Talinum triangulare on some selected hematological and kidney parameters of experimental rats. World J Pharm Pharmaceut Sci 2: 4383-4396.

11. Folarin OM, Bamiro FO, Esuoso, K.O. 2001. Distribution of nutritive elements in water leaf. Global J Pure Applied Sci 7: 285-290.

12. Gray Jr LE, Ostby J, Furr J, Price M, Veeramachaneni DN, Parks L. 2000. Perinatal exposure to the phthalates DEHP, BBP, and DINP, but not DEP, DMP, or DOTP, alters sexual differentiation of the male rat. Toxicol Sci 58: 350-365.

13. Hutson JM, Southwell BR, Li R, Lie G, Ismail K, Harisis G, Chen N. 2013.The Regulation of Testicular Descent and the Effects of Cryptorchidism. Endocrine Rev 34:725-752.

14. Kasahara E, Sato EF, Miyoshi M, Konaka R, Hiramoto K, Sasaki J, Tokuda M, Nakano Y Inoue M. 2002. Role of Oxidative Stress In Germ Cell Apoptosis Induced By Di(2-Ethylhexyl) Phthalate. Biochem J 365: 849-856.

15. Lehmann KP, Phillips S, Sar M, Foster PM, Gaido KW. 2004. Dose-dependent alterations in gene expression and testosterone synthesis in the fetal testes of male rats exposed to di(n-butyl) phthalate. Toxicol Sci 81: 60-68.

16. Mathur PP, D'Cruz SC. 2011. The effect of environmental contaminants on testicular function.Asian J Androl 13: 585-591

17. Naidu KA. 2003. Vitamin C in human health and disease is still a mystery? An overview. Nutrition ] 2: 7-16.

18. Olajire AA, Azeez L. 2011. Total antioxidant activity, phenolic, flavonoid and ascorbic acid contents of Nigerian vegetables. Afr J Food Sci Technol 2: 022-029. 
19. Parks LG, Ostby JS, Lambright CR, Abbott BD, Klinefelter GR, Barlow NJ, Gray Jr LE. 2000. The plasticizer diethylhexyl phthalate induces malformations by decreasing fetal testosterone synthesis during sexual differentiation in the male rat. Toxicol Sci 58: 339-349.

20. Silins I, Hogberg J. 2011. Combined toxic exposures and human health: biomarkers of exposure and effect. Int J Environ Res Public Health 8: 629-647.

21. Tetz LM, Cheng AA, Korte CS, Giese RW, Wang P, Harris C. 2013. Mono-2-ethylhexyl phthalate induces oxidative stress responses in human placental cells in vitro. Toxicol Applied Pharmacol 268: 47-54.

22. Thorup J, Cortes D, Petersen BL. 2006. The incidence of bilateral cryptorchidism is increased and the fertility potential is reduced in sons born to mothers who have smoked during pregnancy. J Urol 176: 734-737.

23. Uchendu C, Suleiman F, Ambali A, Joseph O. 2012. The organophosphate, chlorpyrifos, oxidative stress and the role of some antioxidants. Afr J Agric Res 7: 2720-2728.

24. Virtanen HE, Bjerknes R, Cortes D, Jørgensen N, Rajpert-De Meyts E, Thorsson AV, Thorup J, Main KM. 2007. Cryptorchidism: classification, prevalence and long-term consequences. Acta Paediatrica 96: 611-616.

25. Wilson VS, Lambright C, Furr J, Ostby J, Wood C, Held G, Gray LE. 2004. Phthalate ester-induced gubernacular lesions are associated with reduced insl3 gene expression in the fetal testis. Toxicol Letters 146: 207-215.

26. Zhao Y, Ao H, Chen L, Sottas CM, Ge RS, Li L. 2012. Mono-(2-ethylhexyl) phthalate affects the steroidogenesis in rat Leydig cells through provoking ROS perturbation. Toxicol In Vitro 26: 950955. 